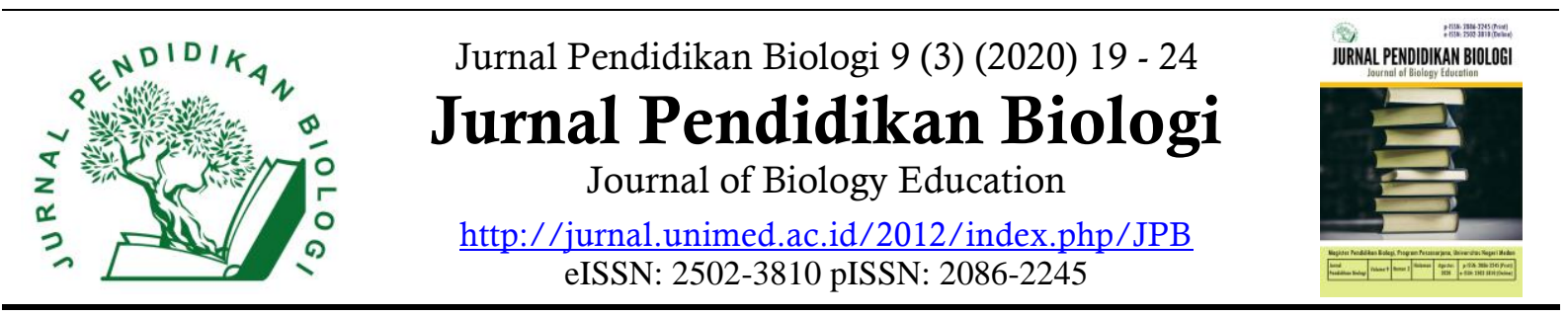

\title{
Penggunaan Model Pembelajaran Collaborative Creativity untuk Meningkatkan Kemampuan Berpikir Kreatif Siswa pada Materi Pencemaran Lingkungan
}

\author{
Naufal Ahmad Muzakki ${ }^{*}$, Fransisca Sudargo ${ }^{2}$, Mimin Nurjhani $^{2}$ \\ ${ }^{1}$ Mahasiswa Program Studi Pendidikan Biologi, FPMIPA, Universitas Pendidikan Indonesia \\ ${ }^{2}$ Program Studi Pendidikan Biologi, FPMIPA, Universitas Pendidikan Indonesia
}

\section{INFO ARTIKEL}

Histori Artikel

Received 29 September 2020

Revised 8 Nopember 2020

Accepted 25 Nopember 2020

Published 1 Desember 2020

Keywords:

Collaborative creativity

learning model,

Creative thinking,

Environmental pollution

\begin{abstract}
The 2013 curriculum applies a scientific approach in the learning proses, therefore students are expected to have higher order thinking skills, one of which is creative thinking. Students' creative thinking skills can be trained by implementing student-centered learning. The purpose of this study was to analyze the using of collaborative creativity learning model on students' creative thinking abilities on the topic of environmental pollution. The method used in this study was a quasi-experiment with a pre-experimental research type and one group pretest-posttest research design. The subjects in this study was class X science 8 Senior High School in Bandung. Creative thinking abilities measured in this study include four aspects: fluency, flexibility, originality, and elaboration. Data of students' creative thinking skills were obtained from the pretest and posttest scores. Based on the results of data processing, the creative thinking ability of students has increased after using collaborative creativity learning model with a gain index value of 0.31 in the medium category. This shows that the use of collaborative creativity learning model can improve students' creative thinking ability on the topic of environmental pollution. The benefit of this research is that the Collaborative creativity learning model can be used as a reference for learning in class.
\end{abstract}

Copyright ( $) 2020$ Universitas Negeri Medan. Artikel Open Access dibawah lisensi CC-BY-4.0 (https://creativecommons.org/licenses/by/4.0)

\section{How to Cite}

Muzakki, N. A., Sudargo, F. \& Nurjhani, M. (2020). Penggunaan Model Pembelajaran Collaborative Creativity untuk Meningkatkan Kemampuan Berpikir Kreatif Siswa pada Materi Pencemaran Lingkungan. Jurnal Pendidikan Biologi, 9(3), 19-24.

\section{PENDAHULUAN}

Pendekatan saintifik diterapkan di kurikulum 2013 dalam proses pembelajarannya, dimana di dalam pembelajarannya siswa dituntun untuk mengamati, menanya, mengumpulkan informasi, menalar/mengasosiasikan, dan mengomunikasikan (Ayuni, 2015). Berpikir tingkat tinggi (higher order thinking skills) diharapakan di miliki oleh setiap siswa. Kemampuan berpikir tingkat tinggi dalam aktivitas pembelajaran sangat berperan untuk mengidentifikasi masalah, mengeksplorasi 
berbagai metode, dan mengeksplorasi alternatif solusi (Astutik et al., 2017). Salah satu kemampuan berpikir tingkat tinggi yang dapat dikembangkan adalah berpikir kreatif (Widodo \& Kadarwati, 2013). Kemampuan berpikir kreatif merupakan salah satu aspek kognitif yang harus diperhatikan dalam proses pembelajaran di kelas karena dengan berpikir kreatif peserta didik akan mencoba persepsi, konsep, dan sudut pandang yang berbeda sehingga peserta didik dapat menggunakan berbagai cara untuk memecahkan masalah, menghasilkan ide atau gagasan yang lebih baik, lebih memuaskan dan lebih kreatif (Wulandari, Liliasari, \& Titin, 2011). Kemampuan berpikir kreatif dapat dibentuk melalui pembelajaran yang menekankan eksplorasi kemampuan peserta didik untuk memecahkan berbagai masalah agar peserta didik mampu mengidentifikasi masalah dan mencetuskan gagasan yang baru mengenai masalah tersebut (McGregor, 2007). Kemampuan berpikir kreatif dapat diukur melalui tes kemampuan berpikir kreatif dalam bentuk sejumlah pertanyaan yang diberikan dalam rangka mengetahui jawaban peserta didik dalam bentuk lisan, tulisan, maupun perbuatan terkait aspek-aspek kreatifitas yang ingin digali (Munandar, 2009).

Selama ini, penerapan pembelajaran di Indonesia kurang untuk mendorong peserta didik untuk berpikir kreatif (Redhana, 2019). Salah satu faktor yang menyebabkan pemikiran kreatif tidak berkembang selama pembelajaran adalah kurikulum yang pada umumnya dirancang dengan target materi yang luas, sehingga pendidik lebih fokus menyelesaikan materi daripada pada proses pengajarannya yang dapat meningkatkan kemampuan berpikir kreatif (Panjaitan \& Surya, 2017). Pada proses pembelajaran, kreativitas peserta didik dalam pemecahan masalah merupakan salah satu aspek yang penting dalam mengembangkan keaktifan (Nadillah, Pramadi, \& Listiawi,
2017). Proses pembelajaran yang berkualitas harus mempersiapkan peserta didik untuk memiliki Scientific literacy, nilai, sikap, dan kemampuan berpikir tingkat tinggi (higher order thinking skills) sehingga akan muncul sumber daya manusia yang dapat berpikir kritis, berpikir kreatif, membuat keputusan, dan memecahkan masalah (Tawil \& Liliasari, 2013).

Salah satu cara yang dapat diperkirakan membantu peserta didik aktif dalam proses pembelajaran adalah dengan menggunakan model pembelajaran Collaborative Creativity. Model ini memungkinkan peserta didik menggunakan dan menggembangkan kemampuan kreativitas ilmiah untuk memperoleh penguasaan konsep saat peserta didik merumuskan permasalahan yang diberikan, merancang percobaan, memperoleh data, mendiskusikan, mengevaluasi ide, merefleksi proses pengumpulan data, dan mempertimbangkan kesimpulan teman (Astutik et al., 2017). Model pembelajaran Collaborative Creativity ini sebelumnya pernah dilakukan penelitian oleh Albertus \& Atrasina (2019) terhadap kemampuan literasi sains dan hasil peneilitian menujukkan bahwa model pembelajaran Collaborative Creativity berpengaruh signifikan terhadap kemampuan literasi. Adapun penelitian model pembelajaran Collaborative Creativity terhadap kemampuan berpikir kreatif pada materi pencemaran lingkungan masih relative sedikit, hal tersebut membuat peneliti ingin menganalisis penggunaan model pembelajaran Collaborative Creativity terhadap kemampuan berpikir kreatif.

Oleh karena itu, berdasarkan permasalahan diatas maka dilakukan penelitian untuk menganalisis penggunaan model pembelajaran Collaborative Creativity untuk meningkatkan kemampuan berpikir kreatif siswa pada materi pencemaran lingkungan. Manfaat yang diharapkan dalam 
penelitian ini, penerapan model pembelajaran Collaborative Creativity bisa dijadikan referensi untuk pembelajaran di kelas dan membantu siswa dalam meningkatkan kemampuan berpikir kreatif.

\section{METODE}

Metode yang digunakan dalam penelitian ini adalah eksperimen dengan jenis penelitian pre-experimental dan desain penelitian One group pretest-posttest (Sugiyono, 2006). Subjek dalam penelitian ini adalah Kelas X MIPA 8 SMAN 1 Bandung yang merupakan salah satu SMA Negeri di Kota Bandung semester genap tahun ajaran 2018/2019, karena setiap kelas di SMAN tersebut memiliki karakteristik yang sama. Jumlah sampel pada penelitian ini adalah 32 siswa.

Instrumen tes yang dipilih yakni tes uraian untuk mengukur kemampuan berpikir kreatif siswa, sedangkan instrumen non-tes yaitu lembar keterlaksanaan sintak model pembelajaran Collaborative Creativity. Kemampuan berpikir kreatif dalam penelitian ini diukur oleh tes yang berisi separangkat soal uraian tentang pencemaran lingkungan yang dikembangkan menggunakan aspek kemampuan berpikir kreatif peserta didik yaitu berpikir lancar (fluency), berpikir luwes (flexibility), berpikir asli (originality), dan berpikir merinci (elaboration) (Munandar, 2009). Tes uraian ini digunakan untuk mengukur kemampuan berpikir kreatif siswa. Tes Uraian terdiri dari 7 soal. Tes uraian ini diberikan kepada siswa sebelum dan sesudah kegiatan pembelajaran.

Selanjutnya dilakukan uji instrumen kepada siswa yang telah mempelajari materi pencemaran lingkungan. Kemudian dilakukan analisis instrumen uji coba butir soal yang bertujuan untuk mengetahui kelayakan perangkat instrumen penelitian. Analisis yang digunakan antara lain, uji validitas, uji reliabilitas, uji daya pembeda, dan uji kesukaran. Analisis dilakukan menggunakan software ANATES V4 yang dioperasikan menggunakan laptop selanjutnya diinterpretasikan dan disimpulkan apakah soal tersebut dapat digunakan atau tidak sebagai alat ukur. Apabila soal tersebut dapat digunakan maka analisis data yang digunakan pada hasil tes uraian pretest dan postest terlebih dahulu dilakukan uji normalitas dengan menggunakan Uji Shaprio-Willk dengan nilai signifikan 0,05 jika data berdistribusi normal akan dilanjutkan dengan Uji Paired Sample TTest dan jika data tidak berdistribusi normal maka akan dilanjutkan dengan uji Wilcoxon

Selanjutnya, instrumen untuk lembar keterlaksanaan sintak model pembelajaran Collaborative Creativity digunakan untuk melihat keterlaksanaan sintak model pembelajaran Collaborative Creativity yang meliputi tahap identifikasi masalah, eksplorasi ide kreatif, Collaborative Creativity, elaborasi ide kreatif, evaluasi proses dan hasil. Format observasi diberikan kepada observer untuk menilai keterlaksanaan model pembelajaran Collaborative Creativity, observer bertugas untuk memberikan tanda Check list $(\checkmark)$ pada kolom yang telah disediakan sesuai dengan aktivitas guru dan siswa yang diobservasi mengenai penggunaan model pembelajaran Collaborative Creativity.

\section{HASIL DAN PEMBAHASAN}

Berdasarkan Tabel 1, data nilai pretest dan posttest yang diperoleh dilakukan uji normalitas terlebih dahulu dengan menggunakan Uji Shaprio-Willk dengan nilai signifikan 0,05 dan diperoleh nilai pada pretest sebesar 0,052 dan postest 0,167 yang artinya data yang diambil dari sampel berdistribusi normal sehingga dapat menggunakan Uji Paired sample T-Test untuk melihat pengaruh dari penggunaan model pembelajaran Collaborative Creativity. 
Tabel 1. Rekapitulasi Data Pretest dan Posttest Kemampuan Berpikir Kreatif Siswa

\begin{tabular}{lcc}
\multicolumn{1}{c}{ Data } & Pretest & Posttest \\
\hline Jumlah Siswa (n) & 32 & 32 \\
Rata-rata & 58,38 & 70,5 \\
Standar Deviasi & 17,03 & 13,88 \\
Nilai Maksimun & 96 & 100 \\
Nilai Minimun & 36 & 52 \\
$\begin{array}{l}\text { Normalitas } \\
\text { (Shapiro-Willk) }\end{array}$ & 0,052 & 0,167 \\
$\begin{array}{l}\text { Paired Sample T-Test Sig. } \\
\text { (2-tailed) }\end{array}$ & \multicolumn{2}{c}{0,00} \\
\hline
\end{tabular}

Berdasarkan hasil Uji Paired sample T-Test yang diperoleh dari nilai pretest dan posttest sebesar $0,00<0,05$ sehingga dapat disimpulkan bahwa ada perbedaan rata-rata nilai antara pretest dan postest yang artinya ada pengaruh dari penggunaan model pembelajaran Collaborative Creativity. Dengan demikian, terdapat pengaruh terhadap kemampuan berpikir kreatif siswa setelah menggunakan model pembelajaran Collaborative Creativity.

Berdasarkan penelitian yang dilakukan oleh Syafi'i, Suryawati, \& Saputra (2011) kemampuan berpikir kreatif siswa dapat ditingkatkan melalui pembelajaran berbasis masalah hal ini juga terdapat pada model pembelajaran Collaborative Creativity yang menekankan masalah dimana siswa dituntun untuk mecari cara/solusi untuk memecahkan masalah tersebut. Pembelajaran Collaborative Creativity bukan hanya menekankan pada masalah tetapi juga menekankan kerja aktif dari siswa dan kerja sama antar anggota kelompok dalam melakukan diskusi hal ini sejalan dengan penelitian yang dilakukan oleh Astutik, Pratiwi, \& Maryani (2018) dimana siswa yang menggunakan model pembelajaran Collaborative Creativity menjadi lebih aktif dan tertarik dalam mengikuti kegiatan diskusi di kelas. Menurut Gokhale (1995) menyatakan bahwa pembelajaran berkelompok dapat memberikan siswa kesempatan berdiskusi dan bertanggung jawab terhadap pembelajaran mereka serta mendorong siswa untuk mengembangkan pengetahuannya.

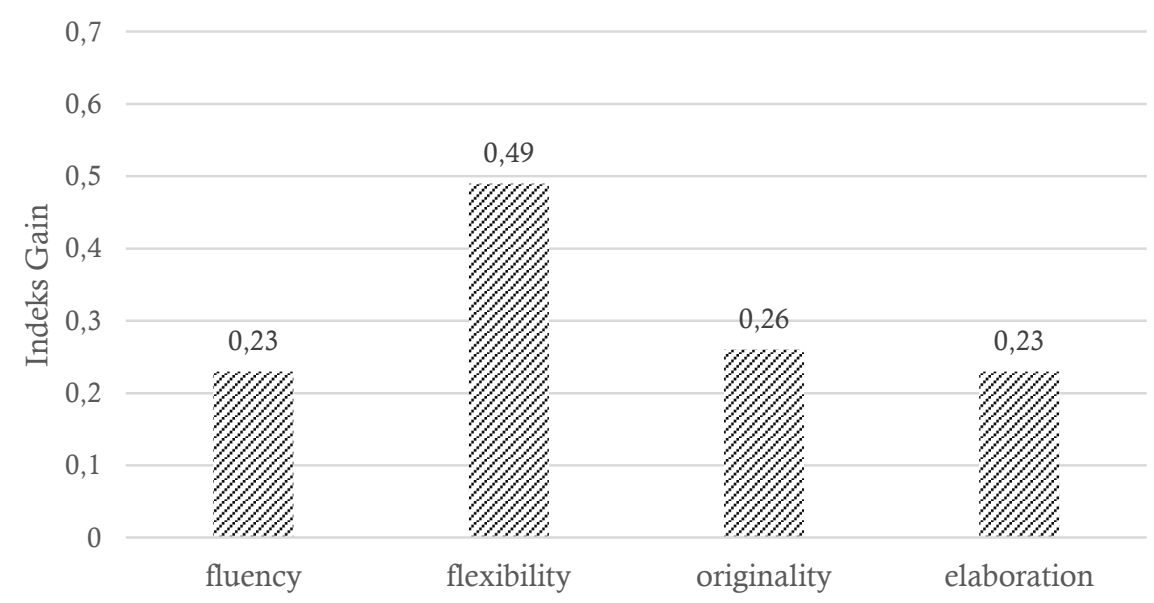

Gambar 1. Nilai Indeks Gain Setiap Aspek Kemampuan Berpikir Kreatif Siswa

Berdasarkan Gambar 1, hasil data penelitian yang diperoleh menunjukkan nilai indeks gain terendah sebesar 0,23 yaitu pada aspek berpikir lancar (fluency) dan berpikir merinci (elaboration), sedangkan indeks gain tertinggi sebesar 0,49 yaitu aspek berpikir luwes (flexibility). Secara keseluruhan rata-rata peningkatan kemampuan berpikir kreatif setelah menggunakan model pembelajaran Collaborative Creativity sebesar 0,31 dengan kategori sedang. Secara keseluruhan kemampuan berpikir kreatif siswa pada materi 
pencemaran lingkungan meningkat setelah menggunakan model pembelajaran collaborative creativity. Kelebihan dari penggunaan model pembelajaran collaborative creativity dapat meningkatkan keterampilan siswa dalam pemecahan masalah dan efektif untuk meningkatkan penguasaan konsep hal ini di dukung oleh penelitian yang dilakukan oleh Fitriyani, Supeno, \& Maryani (2019) yang menyatakan bahwa kegiatan yang kolaboratif dapat membuat siswa diajarkan untuk bertanggung jawab atas tugas yang diberikan kepada setiap individu sebelum akhirnya diintegrasikan dengan solusi yang dihasilkan oleh siswa lain. Dalam pembelajaran collaborative creativity juga membuat siswa aktif dalam berdiskusi kelompok dan saling mengeksplorasi ide-ide setiap anggota kelompok.

Model pembelajaran collaborative creativity pada pembelajarannya menekankan pada kerja tim dan kreativitas ilmiah di mana semua siswa perlu belajar untuk mengeksplorasi pandangan tim, menerapkan logika untuk mempertimbangkan pemikiran rekan-rekan dan metode tim, menghindari keputusan yang terburu-buru, menggabungkan dan membangun ide-ide yang diungkapkan oleh siswa lain dan menemukan cara baru. Menurut Albertus \& Atrasina (2019) kerja secara tim membuat siswa lebih terbuka dalam menerima informasi/gagasan yang disampaikan oleh siswa yang lain hal ini membuat wawasan siswa lebih luas yang akhirnya akan berdampak kepada hasil belajar dan kemampuan literasi siswa.

Kemampuan berpikir kreatif siswa setelah menggunakan model pembelajaran collaborative creativity membuat siswa berusaha mencari sesuatu yang baru dan memberikan solusi alternatif. Siswa selalu ingin menemukan sesuatu yang lebih baik dan lebih efisien. Menurut Baer (1993) bahwa siswa yang memiliki kreativitas menunjukkan berbagai hal, seperti kebiasaaan berpikir, sikap, pembawaan atau kepribadian, atau kecakapan dalam memecahkan masalah. Adapun kekurangan dari pembelajaran ini yaitu apabila di dalam suatu kelompok memiliki kemampuan berpikir yang sama.

Berdasarkan penelitian yang dilakukan oleh Astutik, et al. (2017) keberhasilan menggunakan model pembelajaran Collaborative Creativity dapat terlihat dalam keterlaksanaan sintak. Sintak pembelajaran pada model Collaborative Creativity meliputi identifikasi masalah, eksplorasi ide kreatif, Collaborative Creativity, elaborasi ide kreatif dan tahap terakhir yaitu evaluasi proses dan hasil. Dalam penelitian ini dilakukan observasi untuk mengamati keterlaksanaan sintak pembelajaran Collaborative Creativity oleh satu orang observer dengan mengamati aktivitas guru dan siswa pada saat kegiatan pembelajaran berlangsung. Hasil observasi yang dilakukan oleh observer bahwa setiap sintak pada model pembelajaran Collaborative Creativity terlaksana. Catatan observasi menujukkan bahwa siswa terlihat aktif selama berdiskusi di dalam kelompok dan antusias dalam mengemukakan pendapat/solusi untuk memecahkan masalah yang ada dan peran guru dalam pembelajaran ini memandu dan mengarahkan apa yang harus dilakukan oleh siswa agar sesuai dengan tahapan-tahapan pembelajaran Collaborative Creativity.

\section{KESIMPULAN}

Hasil kemampuan berpikir kreatif siswa sebelum dan setelah penggunaan model pembelajaran collaborative creativity mengalami perubahan dilihat dari nilai Uji Paired Sample TTest sebesar $0,00<0,05$ sehingga dapat disimpulkan bahwa ada perbedaan rata-rata nilai antara pretest dan postest, hal ini menunjukkan bahwa penggunaan model pembelajaran Collaborative Creativity dapat 
meningkatkan kemampuan berpikir kreatif siswa pada materi pencemaran lingkungan. Sintak model pembelajaran Collaborative Creativity terlaksana dengan baik, hal ini ditunjukkan oleh aktivitas guru dan siswa pada keseluruhan sintak model pembelajaran Collaborative Creativity dapat terlaksana.

\section{DAFTAR PUSTAKA}

Albertus, D., \& Atrasina, D. (2019). Pengaruh Model Collaborative Creativity (CC) Terhadap Kemampuan Literasi Sains dan Hasil Belajar Fisika Siswa di SMA. Jurnal Ilmu Pendidikan MIPA, 21(1), 9-22.

Astutik, S., Pratiwi, D., \& Maryani. (2018). Model Pembelajaran Collaborative Creativity (CC) Berbantuan Virtual Laboratory pada Pembelajaran Fisika di SMA. Jurnal Pembelajaran Fisika, 7(3), 229-234.

Astutik, S., Susantini, E., Madladzim, \& Nur, M. (2017). Effectiveness of Collaborative Students Worksheet To Improve Student'S Affective Scientific Collaborative and Science Process Skills (SPS). International Journal of Education and Research, 5(1), 151-164.

Ayuni, F. (2015). Pemahaman Guru Terhadap Pendekatan Saintifik (Scientific Approach) Dalam Pembelajaran Geografi. Jurnal Pendidikan Geografi, 15(2), 1-7.

Baer, J. (1993). Craetivity and Divergent Thinking: A Task Spesific Approach. London: Lawrence Elbaum Associates Publisher.

Fitriyani, R., Supeno, S., \& Maryani, M. (2019). Pengaruh LKS Kolaboratif Pada Model Pembelajaran Berbasis Masalah Terhadap Keterampilan Pemecahan Masalah Fisika Siswa SMA. Berkala Ilmiah Pendidikan Fisika, 7(2), 7181.
Gokhale, A. (1995). Collaborative Learning Enhances Critical Thinking. Journal of Technology Education, 10(1), 13-30.

McGregor, D. (2007). Thinking: Developing Learning a Guide to Thinking Skills in Education. Berkshire, England: Open University Press.

Munandar, U. (2009). Pengembangan Kreativitas Anak Berbakat. Jakarta: Rineka Cipta.

Nadillah, N., Pramadi, A., \& Listiawi, M. (2017). Pengembangan Lembar Kerja Siswa (LKS) Berbasis Project Based Learning Pada Topik Ekologi. Jurnal Skripsi Pendidikan Biologi, 1(4), 17.

Panjaitan, A. H., \& Surya, E. (2017). Creative Thinking (Berpikir Kreatif) Dalam Pembelajaran Matematika. Jurnal Pendidikan IPA Indonesia, 1(12), 2-9.

Redhana, W. (2019). Mengembangkan Keterampilan Abad Ke-21 Dalam Pembelajaran Kimia. Jurnal Inovasi Pendidikan Kimia, 13(1), 2239-2253.

Sugiyono. (2006). Metode Penelitian Kuantitatif \& Kualitatif dan $R \& D$. Bandung: Alfabeta.

Syafi'i, W., Suryawati, E., \& Saputra, A. (2011). Kemampuan Berpikir Kreatif dan Penguasaan Konsep Siswa Melalui Model Problem Based Learning (PBL) dalam Pembelajaran Biologi Kelas XI IPA SMAN 2 Pekanbaru Tahun Ajaran 2010/2011. BIOGENESIS, 8(1), 1-7.

Tawil, M., \& Liliasari. (2013). Keterampilan Berpikir Kompleks dan Implementasinya dalam Pembelajaran $I P A$. Makasar: UNM Press.

Widodo, T., \& Kadarwati, S. (2013). High Order Thinking Berbasis Pemecahan Masalah Untuk Meningkatkan Hasil Belajar Berorientasi Pembentukan Karakter Siswa. Jurnal Cakrawala Pendidikan, 32(1), 161-171.

Wulandari, W., Liliasari, \& Titin, S. (2011). Problem Based Learning untuk Meningkatkan Keterampilan Berpikir Kreatif dan Penguasaan Konsep Siswa pada Materi Larutan Penyangga. Jurnal Pengajaran MIPA, 16(2), 116-120. 